\title{
Hypersensitivity to Aspirin as a Factor for Poor Control in Hereditary Angioedema
}

\author{
Carlos Alberto García-López ${ }^{1 *}$, María Eugenia Vargas-Camaño1, Emmanuel Alcázar-Casarín1, \\ Guillermo Quintana Mexiac1, Pablo León Gómez¹, Mario Alberto Ynga-Durand², \\ Benjamín López-Velázquez ${ }^{1}$, María Isabel Castrejón-Vázquez ${ }^{1}$
}

${ }^{1}$ Servicio Inmunología Clínica y Alergia, Centro Médico Nacional “20 de Noviembre”, ISSSTE, Mexico City, Mexico

${ }^{2}$ Laboratorio de Inmunidad de Mucosas, Sección de Investigación y Posgrado, Escuela Superior de Medicina, Instituto Politécnico Nacional, Mexico City, Mexico

Email: ${ }^{\star}$ calb.garlo@gmail.com

How to cite this paper: García-López, C.A., Vargas-Camaño, M.E., Alcázar-Casarín, E., Mexiac, G.Q., Gómez, P.L., Ynga-Durand, M.A., López-Velázquez, B. and CastrejónVázquez, M.I. (2017) Hypersensitivity to Aspirin as a Factor for Poor Control in Hereditary Angioedema. Journal of Biosciences and Medicines, 5, 39-54.

https://doi.org/10.4236/jbm.2017.53005

Received: January 20, 2017

Accepted: March 19, 2017

Published: March 22, 2017

Copyright $\odot 2017$ by authors and Scientific Research Publishing Inc. This work is licensed under the Creative Commons Attribution International License (CC BY 4.0).

http://creativecommons.org/licenses/by/4.0/

\begin{abstract}
Background: Hereditary angioedema (HAE) is a primary immunodeficiency disorder characterized by $\mathrm{C} 1$ complement inhibitor deficiency and unregulated activation of complement. Aspirin hypersensitivity is related to an increase in the amount of leukotrienes with eosinophil and mast cell activation and increased levels of glandular kallikrein with upregulated local conversion of bradykinin. Both conditions can be present in the same patient. Objectives: We present five patients with HAE; they were all being treated in similar ways according to the therapeuthic options available in our institute (danazol). However, three of them had recurrent episodes of angioedema; in these cases, it was identified aspirin hypersensitivity as a cause of poor disease control. A review of the literature is included. Case Presentation: We present the cases of four females and one male (age range 21 - 58 years) with type I HAE. Subjects were all ISSSTE beneficiaries (state workers) treated at the National Medical Center "20 de Noviembre". Aspirin hypersensitivity was identified in three patients. Elimination of NSAIDs along with dietary elimination of high salicylate-containing foods improved control of angioedema crisis (severe and/ or recurrent episodes). Discussion: Aspirin hypersensitivity was identified as a factor for poor control in our patients with HAE. Such cases improved with dietary elimination of high salicylate-containing foods and avoidance of NSAIDs. Conclusions: This is the first report of patients with HAE and aspirin hypersensitivity as a cause of poor control. We recommend a deliberate search of these comorbidities, especially in cases of poor disease control. Further studies are needed to continue the investigation on this topic.
\end{abstract}

\section{Keywords}

Hereditary Angioedema, Immunodeficiency, Complement, Salicylates 


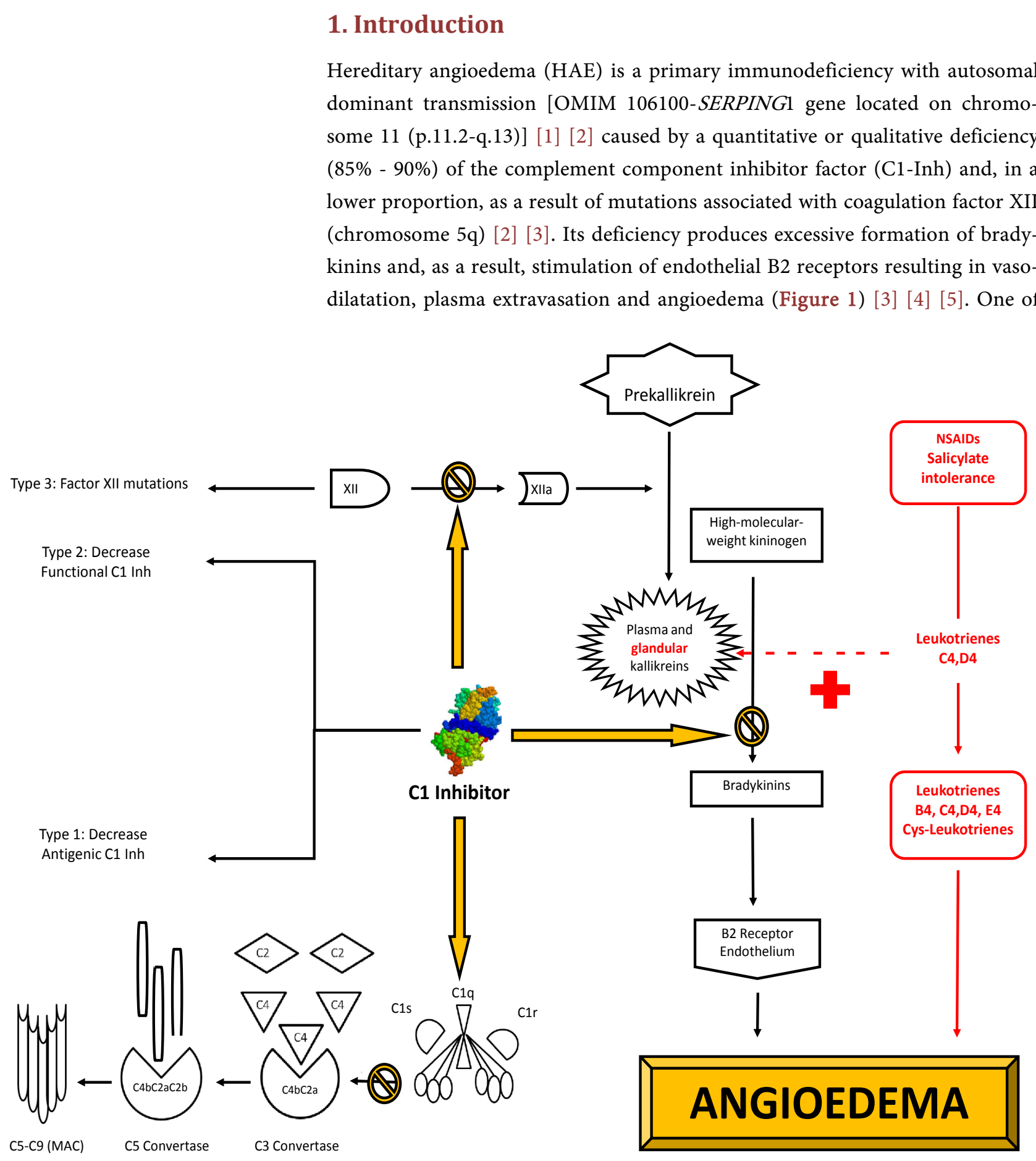

Figure 1. Pathophysiology, classification and association of HAE with hypersensitivity to aspirin. Note: Mutations in the SERPING1 gene cause quantitative and/or functional modifications of the $\mathrm{C} 1$ inhibitor fraction of the complement cascade (types I and II) and mutations in factor XII have repercussions in the contact system (type III). C1 inhibitor regulates (inhibiting) activation of the complement (C1q, C1r, C1s) and contact (plasma and glandular kallikreins) and fibrinolysis (activation of factor XII). Deficiency of this factor favors the constant activation of these systems, thus increasing consumption of complement (low C4), degradation of high- and low-molecular-weight kininogen and activation of the pre-kallikreins, increasing the quantity of bradykinins that will stimulate the B2 receptor among others and resulting in angioedema. NSAIDs and intolerance to salicylates cause angioedema by pathophysiological mechanisms independent of bradykinins (leukotrienes B4, C4, D4, E4, Cys-leukotrienes). Leukotrienes C4 and D4 increase the amount of glandular kallikreins in the lung and intestine, favoring the local conversion of bradykinins in these tissues and, in this manner, aggravating disease evolution. 
the most relevant clinical features is the acute appearance of angioedema (24 - 72 hours) in different parts of the body, affecting even internal organs (intestine, pancreas, larynx, liver). It is usually not accompanied by histaminergic symptoms (pruritus, hives, erythema), nor does it respond to the use of short-costeroids, adrenaline or antihistamines, although there may be exceptional cases where there is also urticaria, caused by another condition, such as allergic diseases [3] [6] [7] [8] [9] and even hypersensitivity to aspirin. It is a rare disease, which can be serious and even fatal, usually underdiagnosed (up to 10 years on average).

Likewise, hypersensitivity to aspirin is a rare condition that can be manifested in different ways. The classic form known as Samter syndrome, is characterized by asthma, nasosinusal polyposis and allergic reactions with the consumption of aspirin and NSAIDs; however, the clinical spectrum of the disease is becoming complex and poorly differentiated, with different phenotypes of the disease, being recognized diverse clinical pictures able to present a concomitant condition of one or several organs which complicates their approach when not it is suspected. Within the mucocutaneous condition, patients usually present with hives, erythema and immediate exanthema, as well as the appearance of angioedema of thebody and internal organs (tongue, larynx, bronchi, small intestine, large intestine, ureter and in general any organ composed of smooth muscle), which may be manifested by isolated angioedema (without urticaria or histaminergic symptoms), abdominal pain and events similar to hereditary angioedema, especially after consumption of aspirin, NSAID's or by ingestion of certain foods and additives with high quantities of salicylates. Elimination of NSAIDs and a diet low in salicylates favored a considerably better clinical evolution. These alterations may be present in patients with hereditary angioedema, and tend to go unnoticed; however, when not identified, these may produce poor disease control. We present five cases of type I HAE, three of which had frequent recurrent episodes identified by hypersensitivity to aspirin.

\section{Case Presentation}

\subsection{Case 1}

We present the case of a 58-year-old female with a family history of recurrent generalized edema without etiological diagnosis in the patient's mother and three brothers. Comorbidities include climacteric syndrome, subclinical hypothyroidism and osteopenia. The patient reported allergy to vitamin B12 (erythema, pruritus and edema). Her disease began at 8 years of age with episodes of intermittent edema with involvement to the face, hands, legs and gluteus without accompanying urticaria or pruritus but exacerbated by menstruation. There were no reports of dyspnea and the patient did not require hospitalization with regard to angioedema. She was evaluated and treated with multiple medications. HAE was suspected 30 years after the initial presentation. Diagnosis of type I HAE was confirmed through laboratory and clinical findings (Table 1). Treat- 
Table 1. General characteristics of patients with HAE.

\begin{tabular}{|c|c|c|c|c|c|}
\hline Findings & Case 1 & Case 2 & Case 3 & Case 4 & Case 5 \\
\hline Age at initiation (years) & 8 & 18 & 25 & 8 & 51 \\
\hline Gender & $\mathrm{F}$ & $\mathrm{F}$ & $\mathrm{F}$ & M & $\mathrm{F}$ \\
\hline HFA & Yes & Yes & No & No & Yes \\
\hline Hospitalizations & No & Yes & Yes & Yes & Yes \\
\hline IOT/UCI & No & Yes & Yes & No & Yes \\
\hline $\begin{array}{l}\text { Urticaria and/or } \\
\text { histamingergic } \\
\text { manifestations }\end{array}$ & No & No & $\begin{array}{c}\text { Yes } \\
\text { (sun, pineapple, pepper, } \\
\text { NSAIDs) }\end{array}$ & No & $\begin{array}{c}\text { Yes } \\
\text { (mint, condiments, } \\
\text { vegetable products, } \\
\text { NSAIDs) }\end{array}$ \\
\hline Complement C4 (mg/dl) & 8.9 & 5.8 & 10 & 6 & 4 \\
\hline $\begin{array}{l}\text { Complement } \\
\text { C4 (2a) }\end{array}$ & $<10$ & 6 & 18 & 1.5 & 6 \\
\hline $\begin{array}{l}\mathrm{C} 1 \text { inhibitor }(\mathrm{mg} / \mathrm{dl}) \\
(\text { normal } 21-39 \mathrm{mg} / \mathrm{dl})\end{array}$ & 4.8 & 11.3 & 5.1 & 0 & 0 \\
\hline $\begin{array}{l}\mathrm{C} 1 \text { inhibitor }(\mathrm{mg} / \mathrm{dl}) \\
(\text { confirmed })\end{array}$ & 11 & 14.2 & 5.9 & 9.6 & 0 \\
\hline HAE type & I & I & I & I & I \\
\hline $\begin{array}{c}\text { Pharmacological } \\
\text { treatment }\end{array}$ & $\begin{array}{l}\text { Danazol } \\
\text { LMWH }\end{array}$ & $\begin{array}{l}\text { Danazol } \\
\text { LMWH }\end{array}$ & $\begin{array}{l}\text { Danazol } \\
\text { LMWH }\end{array}$ & $\begin{array}{l}\text { Danazol } \\
\text { LMWH }\end{array}$ & $\begin{array}{l}\text { C1Inh synthetic } \\
\text { analogues } \\
\text { Antagonists BR2 } \\
\text { LMWH }\end{array}$ \\
\hline Adverse treatment effects & None & None & $\begin{array}{l}\text { Abnormal uterine } \\
\text { hemmorhage }\end{array}$ & Growth delay & $\begin{array}{l}\text { Steatohepatitis } \\
\text { Urticaria } \\
\text { Anaphylaxis }\end{array}$ \\
\hline Triggers of angioedema & $\begin{array}{l}\text { Suspension of } \\
\text { danazol } \\
\text { Stress } \\
\text { Menstrual cycle }\end{array}$ & $\begin{array}{c}\text { Suspension of } \\
\text { danazol Infections } \\
\text { Stress } \\
\text { NSAIDs }\end{array}$ & $\begin{array}{c}\text { Stress } \\
\text { NSAIDs } \\
\text { High } \\
\text { salicylate-containing } \\
\text { foods }\end{array}$ & Stress & $\begin{array}{c}\text { Infections } \\
\text { Stress } \\
\text { NSAIDs } \\
\text { High } \\
\text { salicylate-containing } \\
\text { foods }\end{array}$ \\
\hline $\begin{array}{l}\text { Decrease in number of } \\
\text { episodes following } \\
\text { suspension of NSAIDs } \\
\text { and salicylates }\end{array}$ & No & Yes & Yes & No & Yes \\
\hline
\end{tabular}

HFA, hereditary family antecedents; OTI, orotracheal intubation; ICU, intensive care unit; HAE, hereditary angioedema; NSAIDs, nonsteroidal antiinflammatory drugs; LMWH, low-molecular-weight heparin.

ment was initiated with danazol, decreasing the number of episodes per year, the duration (hours), and intensity of the edema. The patient is currently in good health and is being treated with danazol (100 mg - $400 \mathrm{mg}$ daily) and low-molecular-weight heparin (LMWH) during prodromal phases. She demonstrated response to treatment and her condition remains stable without complications in liver function and without consequences in regard to quality of life. 


\subsection{Case 2}

We present the case of a 57-year-old female with a family history of an angioedema crisis and dyspnea in her deceased mother. The patient's personal medical history included total hysterectomy with salpingo-oophorectomy at 32 years of age due to septic abortion, postsurgical early menopause, hypercholesterolemia, osteoarthritis and facial angioedema after NSAID ingestion in 1997. Her current illness began at 18 years of age, presenting with intermittent episodes of facial, back and hand edema, without rash or pruritus, associated with abdominal pain, and lasting $<72 \mathrm{~h}$. She was hospitalized on only one occasion for dyspnea without complications. The patient associated the appearance of these events with upper respiratory tract infections and emotional stress. She was referred to our services after 22 years of disease presentation. Clinical evolution and laboratory tests confirmed the diagnosis of type I HAE (Table 1). She has been treated with danazol (100 - $400 \mathrm{mg} /$ day) and low molecular weight heparin (LMWH) during prodromal phases, with a slight improvement and with one to two monthly episodes. In 2007 she had facial angioedema and facial and laryngeal edema after ingestion of NSAIDs, which required orotracheal intubation. She has experienced frequent exacerbations since that time. Due to the history of NSAIDtriggered events (two previous episodes and one severe), the patient was advised to avoid NSAIDs and ingest a diet low in salicylates, noting improvement after 6 weeks characterized by an increase in the number of episode-free days. The patient has remained free of angioedema events for 2 years along with a decrease in symptom severity (Figure 2). Her condition is currently being controlled with danazol which, to date, has not caused any alterations in liver function, low-salicylate diet and avoidance of NSAIDs.

\subsection{Case 3}

We present the case of a 43-year-old female with a personal medical history of sulfur and penicillin allergies (erythema, urticaria and angioedema). She was treated with specific immunotherapy with allergens (Chenopodium, Dermatophagoides pteronyssinus) for 2 years due to allergic rhinitis. She reported acute urticaria after sun and heat exposure. The patient reported hemithyroidectomy at 30 years of age due to left thyroid nodule (follicular adenoma), secondary hypothyroidism, tineacorporis, and hyperprolactinemia secondary to pituitary microadenoma. Her current illness began at 21 years of age when she experienced laryngeal edema secondary to NSAID ingestion (naproxen), requiring hospitalization and advanced airway management. At 25 years of age she presented spontaneous generalized recurrent episodes of angioedema with and without urticaria. She was hospitalized on two occasions as a result of facial edema associated with respiratory distress and requiring orotracheal intubation and mechanical ventilatory support. The patient was evaluated in our service 4 years after symptom initiation. After the diagnostic approach based on the clinical evaluation and complementing the laboratory findings, a diagnosis of hereditary type I HAE was made (Table 1). Treatment with danazol was administered (100 - 
$400 \mathrm{mg} / 24 \mathrm{~h}$ ) with notable initial improvement. This treatment was suspended due to abnormal uterine bleeding (uterine myomatosis), a period in which the angioedema events again increased. Hysterectomy was performed by the $\mathrm{OB} /$

CASE 1

$\begin{array}{cc}1957 & 1999 \\ \text { Born } & \text { Diagnosis }\end{array}$

$\begin{array}{ll}1965 & \\ \text { Initiation of } \\ \text { angioedema }\end{array}$

CASE 2

2008-2015

No episodes of

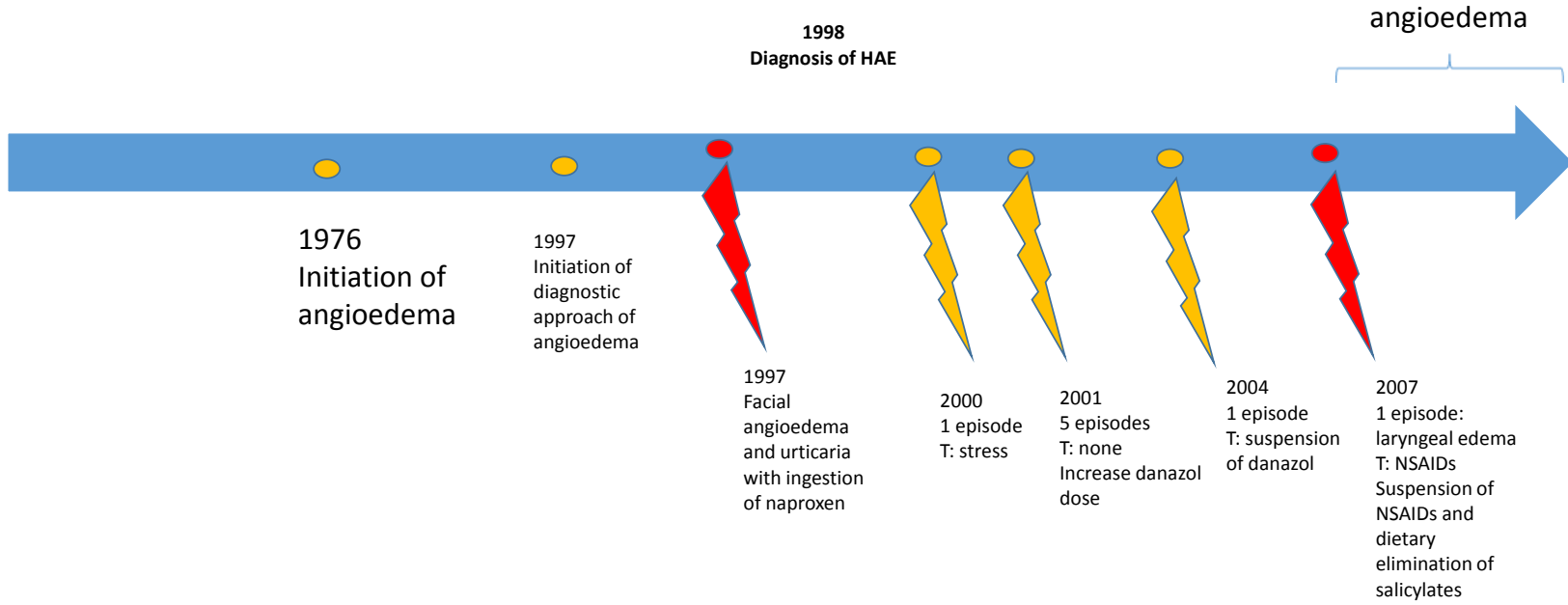

CASE 3

2011-2015

No episodes of

1998

angioedema

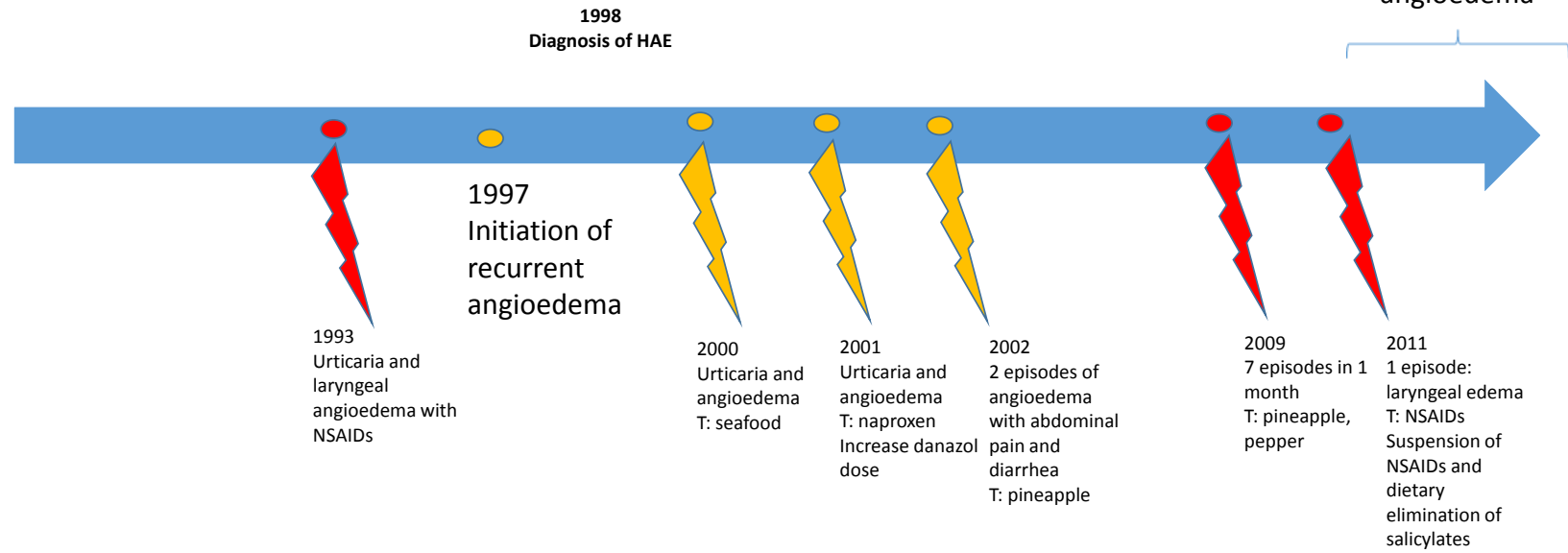




\section{CASE 4}

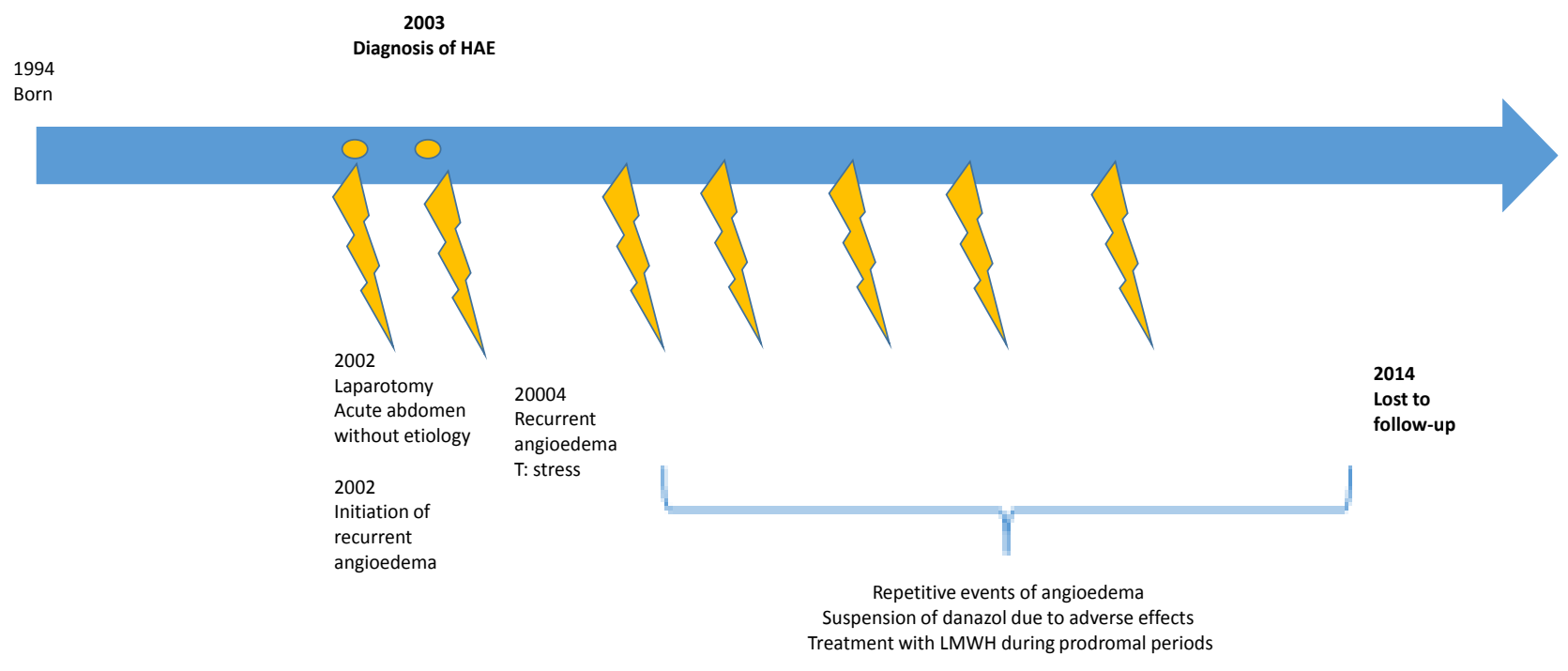

CASE 5

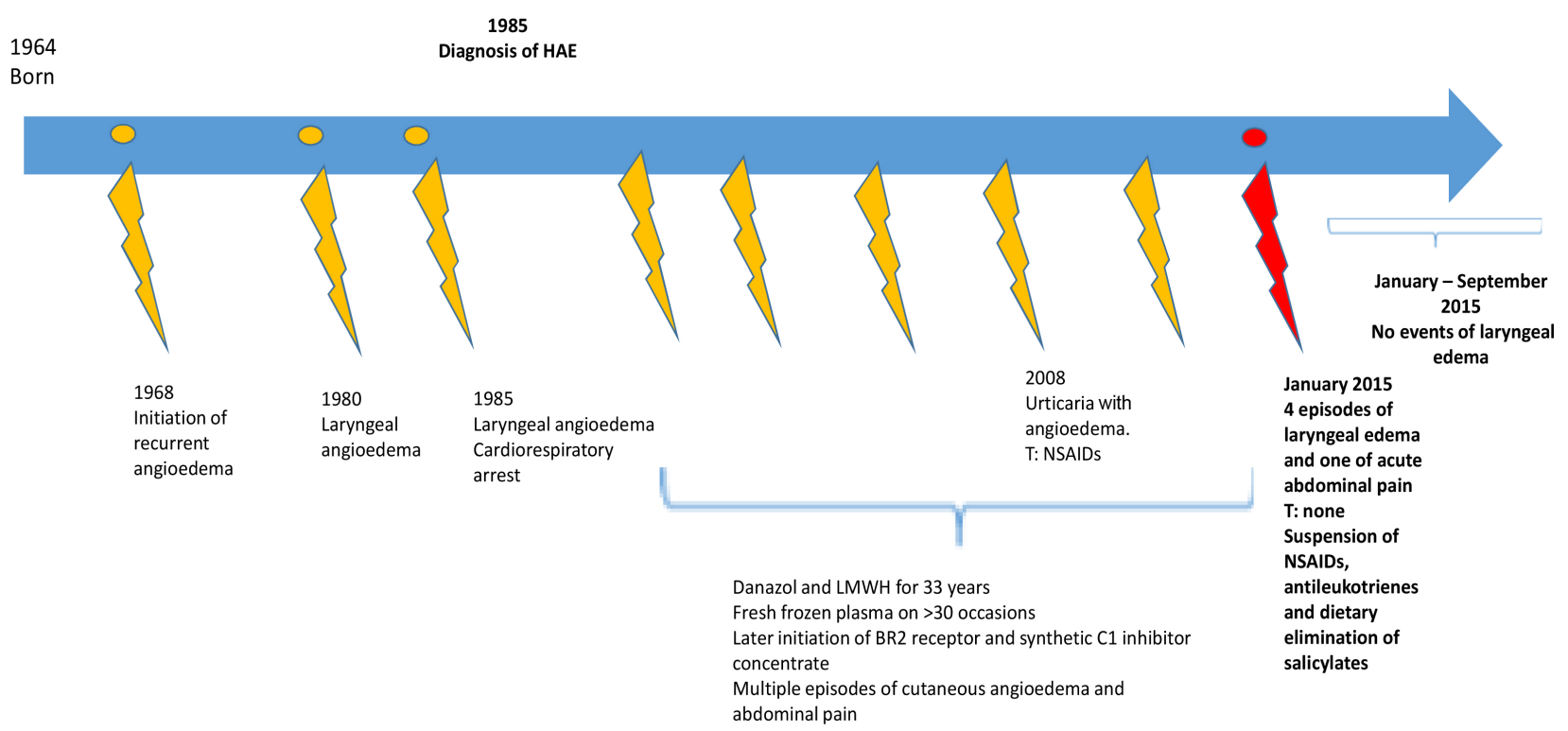

Figure 2. Description of evolution of patients with hereditary angioedema (HAE). Red marks show events triggered (T) due to ingestion of NSAIDs or salicylates.

GYN service, reinitiating danazol at the usual dose and LMWH in prodromal periods. Despite this, symptoms persisted with worsening, reporting seven episodes of angioedema per month. An association was detected with eating pineapple and pepper, as well as an episode of laryngeal edema after ingestion of NSAIDs. The patient was advised to totally avoid NSAIDs and to ingest a lowsalicylate diet, with considerable improvement in regard to the number and severity of episodes. She reported no new events of laryngeal edema (most recent in 2011) and less than one episode of angioedema bimonthly (Figure 2). She is 
currently under surveillance with salicylate restrictions.

\subsection{Case 4}

We present the case of a 21-year-old male with a medical history of laparatomy for abdominal symptoms suggestive of acute appendicitis without diagnostic confirmation. The patient presented stress-related recurrent episodes of edema without urticaria postoperatively (right hand and face), abdominal pain and dyspnea. He was hospitalized for brief periods for monitoring and control of complications. Diagnosis of type $1 \mathrm{HAE}$ was made through clinical evolution and laboratory findings (Table 1). He was treated with danazol from the age of 9 years and remained symptom free for 1 year. Increase of danazol was prescribed because of poorly controlled symptoms but was suspended due to presentation of growth delay. Since that time, treatment with LMWH was indicated with recurrent pictures of angioedema in different forms. The patient was lost to follow-up in the first semester of 2014 as a result of failing to appear for outpatient consultation.

\subsection{Case 5}

We present the case of a 51-year-old female. Family medical history included mother who was deceased at 47 years of age due to angioedema with a laryngeal component. One sister, one brother and four paternal cousins (one male and three females) were diagnosed with HAE. The patient's non-medical personal history included frequent ingestion of mints, condiments and a high consumption of vegetables. Past medical history included adverse reactions to multiple medications: penicillin, nitrofurantoin, phosphomycin, IV omeprazole, acetylsalicylic acid, and NSAIDs (angioedema and urticaria) along with hypothyroidism, dyslipidemia, hypertriglyceridemia, glucose intolerance, gastroesophageal reflux and vitiligo. Surgical history included tonsillectomy, hysterectomy, and appendectomy of normal appendix. From 4 years of age she presented frequent recurrent bouts of abdominal pain and palpebral and labial angioedema, which persisted up to 10 years of age. At 16 and 21 years of age she presented an episode of laryngeal angioedema, causing a second cardiorespiratory arrest requiring intubation and tracheostomy. Type 1 HAE was diagnosed (Table 1). She received fresh frozen plasma transfusions during the angioedema crisis on $>50$ occasions. The last episode (December 2008) caused urticaria and angioedema. She received danazol for 15 years but this treatment was terminated due to steatohepatitis. The patient has received LMWH for 18 years during prodromal phases. Since 2008, the patient has received icatibant (a BR2 receptor antagonist) and since 2014 has received a C1-Inh concentrate. She demonstrated better evolution with this treatment (decrease in the number of events). The patient was referred for evaluation in 2014. Despite treatment, she had recurrent and intense abdominal pain requiring hospitalization (January 2015) and episodes of laryngeal edema (four in the previous year with two of the episodes requiring hospitalization), chronic cough and dyspnea (Figure 2). Due to the patient's history (an- 
gioedema with urticaria after NSAIDs and acetylsalicylic acid ingestion, adverse reactions to multiple medication, ingestion of foods with high salicylate content (mints, pepper and vegetables), disease progression was severe and poor disease control was reported despite first-line treatments. Anti-leukotriene was indicated along with avoidance of NSAIDs and a low-salicylate diet. The patient progressed towards improvement and the number of abdominal pain episodes, cough and dyspnea decreased, without new events of laryngeal edema (1 year). Episodes of cutaneous angioedema also decreased. Chronic cholelithiasis and cholecystitis were diagnosed and the patient is awaiting surgery. She is under surveillance and reports a good quality of life.

\section{Results}

We presented five patients with diagnosis of type $1 \mathrm{HAE}$, four females and one male. Ages ranged from 21 - 58 years of age. Diagnostic delay was, on average, 13.7 years (range 1 - 33 years), which is in agreement with literature reports [2] [4]. Family hereditary history ( $80 \%$ positive) and clinical evolution (recurrent episodes of angioedema $<72 \mathrm{~h}$, poor response to antihistamines and corticosteroids) together with low levels of complement factor $\mathrm{C} 4$ were the primary data for diagnostic suspicion. Confirmatory diagnosis and classification was done according to the WHO international diagnostic criteria [1] [2] [4]. Four patients were hospitalized and required specialized interventions at some time during their evolution (orotracheal intubation and abdominal surgery), three of which were associated with severe events of angioedema and two episodes of urticaria with NSAID ingestion. Emotional and physical stress (surgery and invasive procedures), foods with high salicylate content (pineapple and pepper) and NSAID consumption were the triggers identified. Complement $\mathrm{C} 4$ levels and antigenic $\mathrm{C} 1$ inhibitor fraction did not correlate with the evolution and severity of the disease. No deaths were recorded. Based on the availability of medications in Mexico and within the institution, the treatment most commonly used was based on attenuated androgen analogs and LMWH, with the dose being adjusted during medical consultation based on the evolution of each case (number, duration and severity of episodes per month). Severe adverse effects secondary to this treatment were abnormal uterine bleeding, steatohepatitis and growth delay. Two patients required fresh frozen plasma transfusion and one patient received administration of icatibant and CI-Inh concentrate due to the severity of the disease and to not being a candidate for second-line treatments.

In Mexico, prior reports have been published with characteristics similar to the cases presented here [5] [6] [7]; however, recurrence and severity of the episodes associated with NSAID ingestion and foods high in salicylate content were triggers found in this group of patients and reported for the first time. Clinical improvement after elimination of those triggers is highlighted (Figure 2).

\section{Discussion}

HAE is a primary immunodeficiency disorder with autosomal dominant trans- 
mission [1] [2] and with a variable prevalence (1:6000-1:50,000 persons) [7] [8] [9] [10] characterized by the quantitative deficiency of the (type 1) C1 esterase inhibitor (C1Inh). C1-Inh is a $110-\mathrm{kDa}$ glycoprotein that regulates activation of the complement cascade and fibrinolysis [11]. Its main function is to inhibit the C1r, C1s, MASP-1 and MASP-2 proteases and halt activation of the cascade. In addition, it functions to inhibit proteases of the contact system (plasma kallikrein and activated Hageman factor XIIa and XIIf), which are responsible for the clinical course in HAE. Finally, it exerts inhibitory effects on plasmin and protease Xia (coagulation pathways) [11]. It is considered a suicide protein whose mechanism of action is to form 1:1 stoichiometric complexes with the proteases, thus allowing its clearance and inactivation [11]. The clinical result of the C1Inh deficiency is a state of constant activation of the complement, coagulation and contact systems, with the consequential action of consumption of the uncontrolled complement, interference in the coagulation system and increase in the amount of bradykinins, the latter being responsible for stimulating B2 receptors (BR2) in endothelial cells. This results in phosphorylation of VEcadherins, contraction of the cytoskeleton, loss of intercellular junctions and increase in nitric oxide [1] [10] producing vasodilatation, plasma extravasation with free movement of water and clinically expressed as angioedema (Figure 1). Bradykinins are inactivated by enzymes known as kininases [11] (ACE), aminopeptidase P, dipeptidyl-peptidase IV, carboxypeptidase $\mathrm{N}$, and neutral endopeptidase) [12] [13]. In patients with HAE, these enzymes become insufficient for inactivating the huge amount of serum bradykinins produced by the uncontrolled activation of the complement-contact-coagulation systems as a result of the absence of its inhibitor (C1-Inh). For this reason, use of drugs that interact with these enzymes (ACE inhibitors, ARA, dipeptidyl peptidase IV inhibitors) promote poor disease control with more frequent and severe episodes [4] [10] [11] [14] [15]. There are other rarer mutations that cause HAE associated with coagulation factor XII (type III angioedema) [1] [16], which are manifested clinically under conditions that cause an increase in the amount of estrogen (e.g., pregnancy, contraceptive use, etc.).

NSAID consumption is a factor associated with poor control; however, hypersensitivity to aspirin has not been reported as a crisis-triggering factor [17]. Hypersensitivity to aspirin is a reaction independent of genetically programmed antigen-antibody interactions that occur after contact with acetylsalicylic acidcontaining substances derived from organic and inorganic acids [12] [18]. Risk factors for acquiring this hypersensitivity are viral infections, autoimmune diseases, genetic alterations and pharmacological metabolism [19] [20]. Clinically, it may demonstrate respiratory or skin manifestations and is dependent on the dose and route of salicylate administration. The classic respiratory triad involves asthma, chronic rhinosinusitis with nasal polyposis, and acute upper and lower respiratory tract reactions. Skin and mucosal reactions demonstrate variable intensity and presentation, ranging from urticaria and angioedema to glottic, lingual and pharyngeal edema. Both presentations may lead to anaphylactic shock 
with bronchoconstriction and hyperproduction of mucus (dyspnea, respiratory arrest) [13] [21] [22] [23] [24] [25], abdominal pain caused by contraction of the non-vascular smooth muscle in the digestive tract [26] [27], and cardiovascular manifestations such as hypotension and tachycardia due to smooth muscle vasodilatation. Typically, these present after the first $4 \mathrm{~h}$ of NSAID consumption or after a high dose of salicylates in the diet (foods with preservatives and colorants [12] [13] [20]-[25] fruits, vegetables, herbs, spices, teas, marmalades and honey) [20] [23] [25]. A normal mixture in the diet contains 10 - $200 \mathrm{mg}$ daily of salicylates; however, in persons who are vegetarians or who consume condiments, spices and additives in large quantities, this is demonstrated to be the equivalent of daily consumption of $75 \mathrm{mg}$ of aspirin [26]. Pathophysiological mechanisms of hypersensitivity to aspirin are diverse [12] [13] [17] [20]-[25] and include marked inhibition of cyclooxygenase 1 (COX-1), inhibition of COX-2 gene transcription [23] [24] [25] [26] [27], degranulation of yeast cells [23] [24] [25] [26] [27] and eosinophil activation [25]. Previously, in vitro and in vivo effects of salicylates on the complement system have been previously studied [28] [29] [30]. Controversial results were reported in relation to their activation and inhibition; however, these results were demonstrated in healthy persons. Skin and mucous membrane symptoms are the result of control and/or activation of the enzymes responsible for the metabolism of the leukotrienes [20] (e.g., leukotriene A4 hydrolase and leukotriene C4 synthesis.) These pathways strongly favor the production of cys-leukotrienes and leukotrienes C4, D4 and E4, thereby causing symptoms [26] [27]. Another mechanism involved exercised by the B4 leukotriene is chemotaxis and activation of T cell CD8 suppressors, inhibition of CD4+ T cell cooperative immune response and IgE synthesis [26] [27].

Diagnosis of this entity is based principally on the clinical history. The most relevant data are gender (females), development of symptoms in the first hours after ingestion of one or more NSAIDs and patients with multiple adverse drug reactions [18]. Skin tests are used to evaluate the IgE-mediated reactions (type 1 hypersensitivity) and the in vitro methods have not been sufficiently validated [18]. The gold standard of the diagnostic tests is the oral medication challenge; however, this test has certain limitations because the main cause of hypersensitivity to aspirin is the cross reactivity between the different drug groups present in up to $76 \%$ of the cases, making test interpretation difficult [18]. Some authors suggest using this test as the last option due to the possible adverse events [17] [18] [20]. Considering this test in patients with HAE may be a little viable maneuver due to the high risks of triggering a serious or even deadly event; however, our patients showed severe problems related with the consumption of NSAIDs according to their clinical history. For this reason, the diagnosis was taken into consideration based on the clinical history as well as the restriction of salicylates (diet and drugs) which, together, have reported a sensitivity $>90 \%$ [18]. Although there is lack of consensus regarding the time and manner of suspension or reduction of salicylates derived from foods, elimination diets are generally recommended for 6 weeks followed by reintroduction of foods to test the ef- 
fectiveness of the strategy and is considered a tool to support the diagnosis [26]. Many studies have demonstrated that individuals with aspirin-induced urticaria respond to the dietary restriction in up to $75 \%$ of the cases [20] [23] [26]. An even more interesting point is that at the experimental level the effect of leukotrienes $\mathrm{C} 4$ and $\mathrm{D} 4$ on kallikreins (enzymes responsible for producing bradykinins) has been reported.Jin et al. [31] demonstrated that administration of leukotrienes $\mathrm{C} 4$ and $\mathrm{D} 4$ in guinea pigs conditioned a direct and dose-dependent increase on the glandular secretion of kallikreins (calciform and mucous-producing cells in the lung and intestine) responsible for transforming the low-molecular-weight kininogen in lis-bradykinins at the local level which, added to the effects caused by the leukotrienes, would help to explain the poor disease control of patients with HAE and salicylate intolerance. These authors also showed that adding an anti-leukotriene decreases the local release of kallikreins and therefore may be considered an alternate treatment option, such as used in Case 5 presented here.

We are aware that the treatment used in the majority of our patients is not the usual first-line treatment reported [8] [10], which may be controversial in the case series. For this reason, we attempted to contrast the cases with control patients with HAE without hypersensitivity to aspirin and who with the same treatments administered had a different evolution (Figure 2). In our environment, access to treatments considered "first line" is not readily available, even in high-specialty hospitals. Previous studies in Mexico [5] [6] [7] where treatments used were considered as second-line drugs (attenuated androgen analogues in conjunction with LMWH) reported primarily good control under strict surveillance due to the adverse effects [32]-[38]. Due to the awareness that this disease can present itself as a comorbidity with other allergic and autoimmune etiologies [12] [24] [39]-[45], the authors consider it important to report these cases especially in scenarios where patients are refractory to treatment because that may be the cause of poor disease control. In the face of clinical suspicion, it would be convenient to consider dietary restriction and avoidance of NSAIDs, which involves minimal risks for patients and may provide benefits in the evaluation as resulted in our limited series. We suggest that the decrease in the number of episodes of angioedema for 1 year, disappearance of abdominal symptoms (chronic pain), severity of events and decrease of additional symptoms (cough, pharyngeal edema) should be considered as a positive response. Mortality due to HAE in general could reach $35 \%$ per episode, especially when there is involvement of the larynx or digestive organs (pancreatitis, cholecystitis, intestinal obstruction). This is a frequent cause of non-surgical acute abdomen because up to $50 \%$ of patients may present these types of symptoms during their lifetime [43]. The association of HAE-hypersensitivity to aspirin may increase even more the risk of mortality. We are aware of the limitations of the scientific impact of the case reports; however, we also believe that this may not be a casual association. Due to the peculiarity of the patients and because there is no prior information with respect to the topic, our team decided to continue with the suspension of salicy- 
lates without subsequent reintroduction. This resulted in a positive effect on patient evolution. Undoubtedly, further investigations of this topic are necessary.

\section{Conclusions}

1) HAE results from autosomal dominant transmission. Diagnosis should be based on the criteria of the World Allergy Organization, which includes a complete clinical history (family history, angioedema with a raised pattern and spontaneous resolution in $72 \mathrm{~h}$ ), low levels of $\mathrm{C} 4$ and alterations in the measurements of the $\mathrm{C} 1$ inhibitor (quantitative and qualitative) or, more rarely, factor XII mutations among others.

2) The pathophysiolological mechanism of HAE is the excessive production of bradykinins with lack of regulation and functions it exercises on the B2 receptor of endothelial cells (vasodilatation, free flow of water and fluid extravasation). In hypersensitivity to aspirin, leukotrienes C4 and D4 cause an increase in glandular secretion of kallikreins at the pulmonary and intestinal level, which increases local production of bradykinins and thereby favors lack of control in angioedema. Both mechanisms could be present in the same patient, and this factor can simulate a bad evolution of hereditary angioedema.

3) Patients with HAE could present comorbidities such as allergic reactions and autoimmune diseases, and in the experience of the authors, hypersensitivity to aspirin could be considered in cases refractory to treatment. It may be that this variable is found only in the Mexican population as described in this report. Implementation of a salicylate-free diet in susceptible patients is a good cost-effective maneuver that may help to make diagnosis and improve disease evolution.

4) Subsequent investigations are required to prove this hypothesis as well as potential therapeutic interventions.

\section{Acknowledgements}

We thank Sharon Morey for technical and editorial assistance.

\section{Declaration of Conflicting Interests}

The authors declare that there is no conflict of interest.

\section{References}

[1] Zuraw, B. (2010) The Pathophysiology of Hereditary Angioedema. World Allergy Organization Journal, 3, 25-28. https://doi.org/10.1186/1939-4551-3-s3-s25

[2] Online Mendelian Inheritance in $\operatorname{Man}^{\star}$. An Online Catalog of Human Genes and Genetic Disorders. http://www.omim.org/entry/106100

[3] Cichon, S., Martin, L., Hennies, H., Müller, F., Van Driessche, K., et al. (2006) Increased Activity of Coagulation Factor XII (Hageman Factor) Causes Hereditary Angioedema Type III. The American Journal of Human Genetics-Cell, 79, 10981104.

[4] Bowen, T., Cicardi, M., Farkas, H., Bowen, T., Farkas, H., Bork, K., Kreuz, W., et al. 
(2010) International Consensus Algorithm for the Diagnosis, Therapy and Management of Hereditary Angioedema. Allergy, Asthma \& Clinical Immunology, 6, $1-13$.

[5] Velasco, A. (2011) Fisiopatología y Advances en el tratamiento del angioedema hereditario. Revista Alergia México, 5, 112-119.

[6] Jiménez, N., Gómez, V., López, T.J., Nieto, M.S. and Pliego, R.C. (2006) Angioedema Hereditario. Comunicación de un caso y revisión de la bibliografía. Revista Alergia México, 53, 34-41.

[7] Lara, A. and Vega, D. (2009) Angioedema Hereditario: Series de casos y actualización de la bibliografía. Revista Alergia México, 5, 48-55.

[8] Tse, K. and Zuraw, B. (2013) Recongnizing and Managing Hereditary Angioedema. Cleveland Clinic Journal of Medicine, 5, 297-308. https://doi.org/10.3949/ccjm.80a.12073

[9] Grumach, A.S. and Kirschfink, M. (2014) Are Complement Deficiencies Really Rare? Overview on Prevalence, Clinical Importance and Modern Diagnostic Approach. Molecular Immunology, 61, 110-117. https://doi.org/10.1016/j.molimm.2014.06.030

[10] Craig, T., Pursun, E., Bork, K., Bowen, T. and Boysen, H. (2012) WAO Guideline for the Management of Hereditary Angioedema. World Allergy Organization Journal, 5, 182-199. https://doi.org/10.1097/WOX.0b013e318279affa

[11] Kaplan, A. (2010) Enzymatic Pathways in the Pathogenesis of Hereditary Angioedema: The Role of C1 Inhibitor Therapy. Journal of Allergy and Clinical Immunology, 126, 918-925. https://doi.org/10.1016/j.jaci.2010.08.012

[12] Raithel, M., Baenkler, H., Naegel, A., Buchwald, F., Schultis, H., Backhaus, B., et al. (2005) Significance of Salicylate Intolerance in Diseases of the Lower Gastrointestinal Tract. Journal of Physiology and Pharmacology, 56, 89-102.

[13] Deutsch, E. and Zalzal, G. (1991) Quincke's Edema, Revisited. Academy of Otolaryngology_Head and Neck Surgery, 112, 100-102. https://doi.org/10.1001/archotol.1991.01870130106026

[14] Johnston, D. (2011) Diagnosis and Management of Hereditary Angioedema. The Journal of the American Osteopathic Association, 111, 28-36.

[15] Davidson, A.E., Miller, S.D. and Klein, D. (1992) Urticaria and Angioedema. Cleveland Clinic. Journal of Medicine, 59, 529-534. https://doi.org/10.3949/ccjm.59.5.529

[16] Björkqvist, J., De, M.S., Lewandrowski, U., Di, G.A., Oschatz, C., Schönig, K., Nöthen, M.M., et al. (2015) Defective Glycosylation of Coagulation Factor XII Underlies Hereditary Angioedema Type III. The Journal of Clinical Investigation, 125, 3132-3146. https://doi.org/10.1172/JCI77139

[17] Suran, F. and Lesley, R. (2009) Unusual Presentation of More Common Diseaseinjury Salicylate Intolerance: A Masquerader of Multiple Adverse Drug Reactions. BMJ Case Reports, 2009, 1602.

[18] Blanca-López, N., Torres, M., Doña, I., Campo, P., Rondón, C., SeoaneReula, M., Salas, M., Canto, G. and Blanca, M. (2013) Value of the Clinical History in the Diagnosis of Urticarial Angioedema Induced by NSAIDs with Cross-Intolerance. Clinical \& Experimental Allergy, 43, 85-91. https://doi.org/10.1111/cea.12013

[19] Jorge, A.S., Dortas, S.D., Valle, S.D. and França, A.T. (2009) Hereditary Angioedema and Chronic Urticaria: Is There a Possible Association? The Journal of Investigational Allergology and Clinical Immunology, 19, 321-339.

[20] Baenkler, H.W. (2008) Salicylate Intolerance: Pathophysiology, Clinical Spectrum, Diagnosis and Treatment. Deutsches Ärzteblatt International, 105, 137-142. 
[21] Gebel, K. and Hornstein, O.P. (1983) Drug-Induced Quincke's Edema of the Mouth Mucosa-An Analysis of 33 Cases. Zeitschrift fur Hautkrankheiten, 58, 1471-1480.

[22] Sardana, N. and Craig, T. (2011) Recent Advances in Management and Treatment of Hereditary Angioedema. Pediatrics, 128, 1173-1180. https://doi.org/10.1542/peds.2011-0546

[23] Hare, L.G., Woodside, J.V. and Young, I.S. (2003) Dietary Salicylates. Journal of Clinical Pathology, 56, 649-650. https://doi.org/10.1136/jcp.56.9.649

[24] Dodig, S. and Richter, D. (2008) Chronic Autoimmune Urticaria in Children. Acta Dermatovenerologica Croatica, 16, 65-71.

[25] Steinke, J.W., Negri, J., Liu, L., Payne, S.C. and Borish, L. (2014) Aspirin Activation of Eosinophils and Mast Cells: Implications in the Pathogenesis of Aspirin-Exacer bated Respiratory Disease. The Journal of Immunology, 193, 41-47. https://doi.org/10.4049/jimmunol.1301753

[26] Sommer, D.D., Hoffbauer, S., Au, M., Sowerby, L.J., Gupta, M.K. and Nayan, S. (2015) Treatment of Aspirin Exacerbated Respiratory Disease with a Low Salicylate diet: A Pilot Crossover Study. Otolaryngology_Head and Neck Surgery, 152, 42-47. https://doi.org/10.1177/0194599814555836

[27] Sivagnanama, P., Koutsoumpas, A. and Forbes, A. (2007) Alimentary Tract Respiratory Symptoms in Patients with Inflammatory Bowel Disease and the Impact of Dietary Salicylates. Digestive and Liver Disease, 39, 232-239.

https://doi.org/10.1016/j.dld.2006.08.001

[28] Hänsch, GM., Voigtländer, V. and Rother, U. (1980) Effect of Aspirin on the Complement System In Vitro. International Archives of Allergy and Immunology, 61, 150-158. https://doi.org/10.1159/000232428

[29] Hänsch, G.M., Voigtländer, V. and Rother, U. (1981) Effect of Salicylates on the Complement System: Generation of Mediators in Vivo and in Vitro. Clinical Immunology and Immunopathology, 21, 228-236. https://doi.org/10.1016/0090-1229(81)90211-7

[30] Voigtländer, V., Hänsch, G.M. and Rother, U. (1980) Effect of Aspirin on Complement In Vivo. International Archives of Allergy and Immunology, 61, 145-149. https://doi.org/10.1159/000232427

[31] Jin, H.Y., Katori, M., Majima, M. and Sunahara, N. (1992) Increased Secretion of Glandular-Kallikrein in the Bronchial Washings Induced by Intravenous Injection of Leukotriene C4 in Guinea-Pigs. British Journal of Pharmacology, 105, 632-638. https://doi.org/10.1111/j.1476-5381.1992.tb09031.x

[32] Helsing, P. and Nielsen, E. (2006) Hepatocellular Focal Nodular Hyperplasia after Danazol Treatment for Hereditary Angioedema. Acta Dermato-Venereologica, 86, 272-273. https://doi.org/10.2340/00015555-0057

[33] Szeplaki, G., Varga, L., Valentin, S., Kleiber, M., Karadi, I., Romics, L., et al. (2005) Adverse Effects of Danazol Prophylaxis on the Lipid Profiles of Patients with Hereditary Angio-Oedema. Journal of Allergy and Clinical Immunology, 115, 864-869. https://doi.org/10.1016/j.jaci.2004.12.1130

[34] Bork, K., Pitton, M., Harten, P. and Koch, P. (1999) Hepatocellular Adenomas in Patients Taking Danazol for Hereditary Angio-Oedema. The Lancet, 353, 10661067. https://doi.org/10.1016/S0140-6736(99)00110-5

[35] Bork, K. and Schneiders, V. (2002) Danazol-Induced Hepatocellular Adenoma in Patients with Hereditary Angio-Oedema. Journal of Hepatology, 36, 707-709. https://doi.org/10.1016/S0168-8278(02)00035-1

[36] Alberti-Flor, J.J., Iskandarani, M., Jeffers, L., Zeppa, R. and Schiff, E.R. (1984) Focal 
Nodular Hyperplasia Associated with the Use of a Synthetic Anabolic Androgen. The American Journal of Gastroenterology, 79, 150-151.

[37] Bartley, J., Loddenkemper, C., Lange, J., Mechsner, S., Radke, C., Neuhaus, P., et al. (2004) Hepatocellular Adenoma and Focal Nodular Hyperplasia after Long-Term Use of Danazol for Endometriosis: A Case Report. Archives of Gynecology and $\mathrm{Ob}$ stetrics, 269, 290-293. https://doi.org/10.1007/s00404-002-0435-Z

[38] Majluf-Cruz, A. and Nieto-Martínez, S. (2011) Long-Term Follow Up Analysis of Nadroparin for Hereditary Angioedema. A Preliminary Report. International Immunopharmacology, 18, 1127-1132. https://doi.org/10.1016/j.intimp.2011.02.007

[39] Narasimhan, R., Lakshman, R., Amos, R. and Williams, L. (2002) Juvenile Dermatomyositis Associated with Hereditary Angioneurotic Oedema. Archives of Disease in Childhood, 87, 563. https://doi.org/10.1136/adc.87.6.563-a

[40] Muhlemann, M.F., Macrae, K.D., Smith, A.M., Beck, P., Hine, I., Hegde, U., Milford-Ward, A., Carter, G.D., Wise, P.H. and Cream, J.J. (1987) Hereditary Angioedema and Thyroid Autoimmunity. Journal of Clinical Pathology, 40, 518-523. https://doi.org/10.1136/jcp.40.5.518

[41] Gelfand, J.A., Boss, G.R., Conley, C.L., Reinhart, R. and Frank, M.M. (1979) Acquired C1 Esterase Inhibitor Deficiency and Angioedema: A Review. Medicine, 58, 321-328. https://doi.org/10.1097/00005792-197907000-00004

[42] Frigas, E. (1989) Angioedema with Acquired Deficiency of the C1 Inhibitor: A Constellation of Syndromes. Mayo Clinic Proceedings, 64, 1269-1275.

https://doi.org/10.1016/S0025-6196(12)61290-7

[43] Karim, Y., Griffiths, H. and Deacock, S. (2004) Normal Comlement C4 Values Do Not Exclude Hereditary Angioedema. Journal of Clinical Pathology, 57, 213-214. https://doi.org/10.1136/jcp.2003.12021

[44] Kaplan, A. (2010) Enzymatic Pathways in the Pathogenesis of Hereditaryangioedema: The Role of C1 Inhibitor Therapy. Journal of Allergy and Clinical Immunology, 126, 918-925. https://doi.org/10.1016/j.jaci.2010.08.012

[45] Davidson, A.E., Miller, S.D. and Klein, D. (1992) Urticaria and Angioedema. Cleveland Clinic Journal of Medicine, 59, 529-534.

\section{Submit or recommend next manuscript to SCIRP and we will provide best service for you:}

Accepting pre-submission inquiries through Email, Facebook, LinkedIn, Twitter, etc. A wide selection of journals (inclusive of 9 subjects, more than 200 journals) Providing 24-hour high-quality service User-friendly online submission system Fair and swift peer-review system Efficient typesetting and proofreading procedure Display of the result of downloads and visits, as well as the number of cited articles Maximum dissemination of your research work

Submit your manuscript at: http://papersubmission.scirp.org/ Or contact jbm@scirp.org 